\title{
A Compact Multi-Band Monopole Antenna using Single Metamaterial for WLAN/WiMAX Applications
}

\author{
Faiza Mouhouche, Arab Azrar, Mokrane Dehmas, Kahina Djafri \\ Laboratory of Signal and Systems, Institute of Electrical and Electronic Engineering, \\ University M'Hamed Bouguara of Boumerdes, Algeria. \\ corresponding author, E-mail: f.mouhouche@univ-boumerdes.dz
}

\begin{abstract}
In this paper, a tri-band printed monopole antenna with electrically coupled metamaterial units is proposed and investigated. The proposed antenna is designed to cover WLAN/WiMAX applications. The structure consists of a printed strip line and two double metamaterial unit cells of different size placed near the monopole antenna on opposite sides. Each unit cell exhibits a negative permeability over the resonance frequency at $2.5 \mathrm{GHz}$ and $3.62 \mathrm{GHz}$, which produces magnetic couplings with the monopole antenna. The proposed structure was fabricated and measured. The measured $-10 \mathrm{~dB}$ bandwidth for the reflection coefficient is from $2.47 \mathrm{GHz}-2.51 \mathrm{GHz}, 3.59 \mathrm{GHz}-3.69 \mathrm{GHz}$, and $5.3 \mathrm{GHz}-$ $7.2 \mathrm{GHz}$, which are suitable for (WLAN: $2.4-2.484,5.15-$ 5.35, and 5.725-5.85 GHz) and (WiMAX: 2.5-2.69, 3.43.8, and 5.25-5.85 GHz) band Applications. By using the switches across the gap of proposed-MTM unit cell, the effect of this unit deactivated and its resonance frequency will disappear. Hence, the proposed antenna maintains the omnidirectional radiation pattern.
\end{abstract}

\section{Introduction}

In the development of wireless communication systems, a multiband antenna has great importance to cover several applications such as WIFI, Bluetooth and WLAN/WiMAX bands. To meet the requirement of multi-band, a printed monopole antenna is an attractive candidate due to its low profile, easy fabrication, simple structure, low cost and omnidirectional radiation pattern. In order to achieve multiband operations, several techniques are used. Multibranched radiators [1], slotted monopoles[2, 3], meander monopoles[4] and fractal shapes[5] are few among them. Recently, an electromagnetic metamaterial is used to improve the antennas performances (gain, bandwidth and size reduction). Metamaterials are artificial materials that exhibit simultaneously negative values of electric permittivity and magnetic permeability over a frequency band[6], Due to the special physical properties that natural materials do not exist, nowadays, the metamaterials are very attractive materials and are applied in many areas of life, such as the microwave invisibility cloaks, the invisible submarines, the revolutionary electronics, the negative refractive-index lenses, the microwave components, as the filters, compact, and efficient antennas[7]. Applying metamaterials to design of antennas is one of its most important applications $[8,9]$.

Metamaterials have been implemented in the resonant antennas to achieve multi-band applications as well as to improve the radiation performances. Several works have been established on metamaterial loaded antennas[10, 11] making the metamaterial unit cell close to the radiating structure[11, 12]. The basic idea behind this approach is that the radiating element is sensitive to the presence of the resonator due to coupling. The presence of the resonating structure improves the antenna radiation characteristics and optimizes the geometric dimensions so that we can obtain an electrically small antenna operating at wireless communication frequencies. The main purpose of this paper is to use a modified triangular form of metamaterial in order to design a multiband antenna. Tow unit cells of the triangular shape of different sizes are placed near the monopole antenna to create three operating bands. The effect of the introduction of the two unit cells is investigated and studied. Moreover, in the aim to more understand the behavior of the metamaterial, the (ON/ OFF) switches are used to study the frequency reconfiguration of the antenna.

\section{Metamaterial unit cell}

Fig.1 shows the proposed unit cell of the metamaterial (proposed-MTM) having the form of a triangle deposited on a dielectric material. The other side of the dielectric material is free from metal. The dielectric substrate is chosen from the existing material and it has the relative permittivity of $\varepsilon_{\mathrm{r}}=4.3$, dielectric loss tangent of $\tan \delta=0.0017$ and a thickness of $\mathrm{h}=1.63 \mathrm{~mm}$.

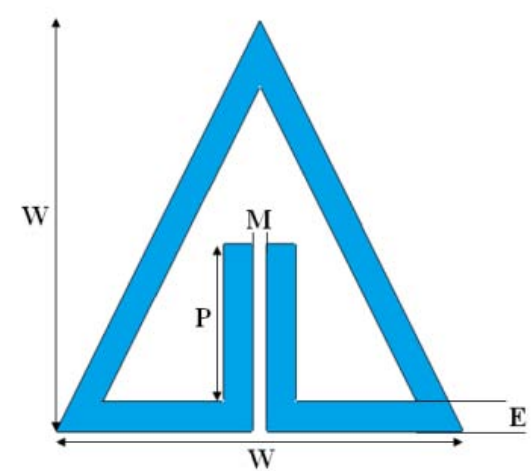

Fig.1 Geometric parameters of the proposed -MTM unit cell with: $\mathrm{W}=9.5 \mathrm{~mm}, \mathrm{E}=0.7 \mathrm{~mm}, \mathrm{M}=0.3 \mathrm{~mm}, \mathrm{P}=4.4 \mathrm{~mm}$. 
The proposed unit cell is designed to get the resonance at 2.5 $\mathrm{GHz}$. The unit cell has been designed and simulated using the finite-difference time domain Computer Simulation Technology (CST) software. The unit cell simulation setup is presented in Fig.2. The proposed-MTM structure was placed between two waveguide ports situated on each side of the $\mathrm{x}$ axis. A perfect electrical conductor (PEC) and perfect magnetic conductor (PMC) boundary conditions are applied along perpendicular to the $\mathrm{y}$ and $\mathrm{z}$ axis, respectively.

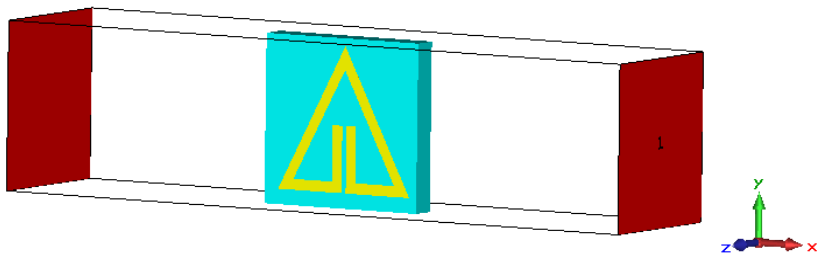

Fig.2 The proposed metamaterial structure between the two waveguide ports.

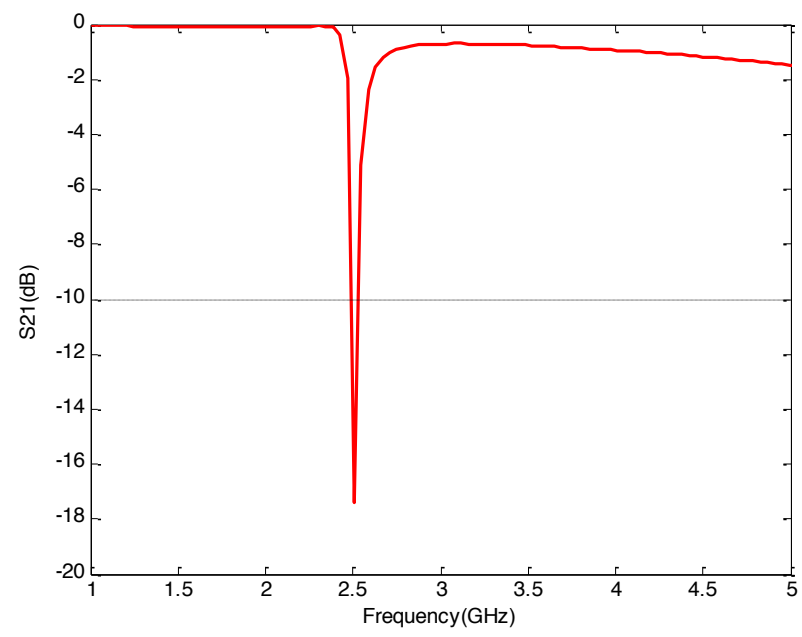

Fig.3 Transmission coefficient $\left(\mathrm{S}_{21}\right)$ of proposed -MTM

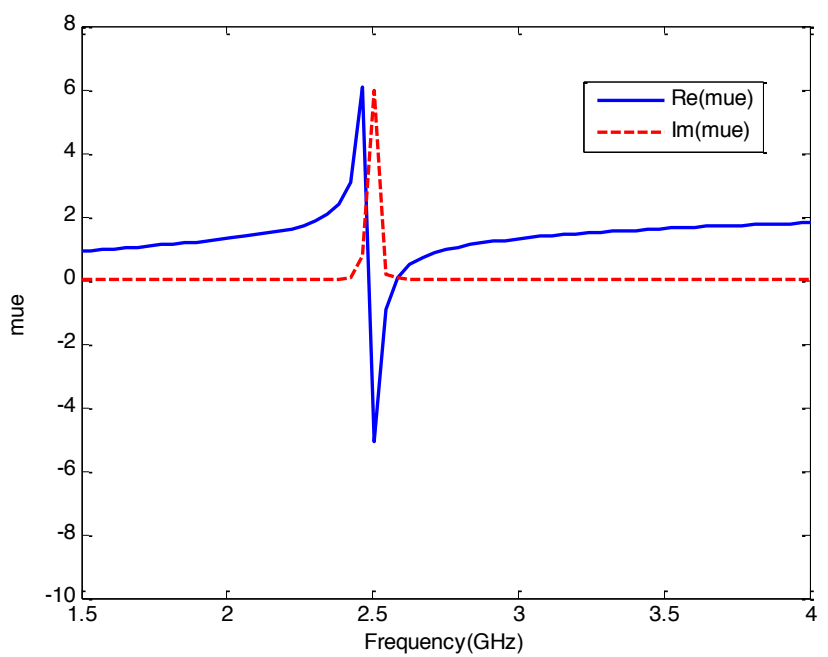

(a)

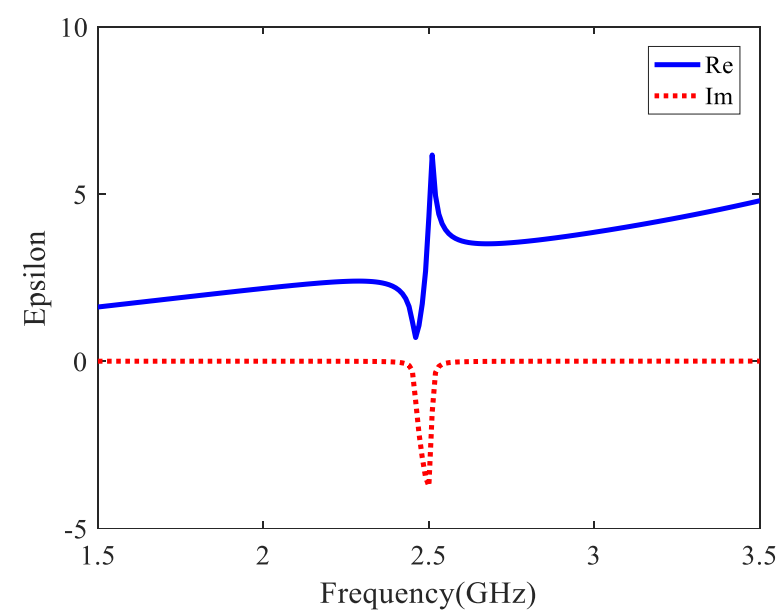

(b)

Fig.4 Retrieved effective parameters of the proposed MTM. (a) permeability, (b) permittivity

The transmission coefficient $\left(\mathrm{S}_{21}\right)$ for the proposed unit cell is shown in Fig.3. From the graph, it is observed that the transmission coefficient $\left(\mathrm{S}_{21}\right)$ is less than $(-10) \mathrm{dB}$ at around $2.5 \mathrm{GHz}$, this means that the resonance frequency of the proposed-MTM is around $2.5 \mathrm{GHz}$. The parameters of the effective medium are extracted from the S-parameters using the retrieval method, a Nicolson-Ross-Weir approach has been used to extract the permittivity and permeability [13]. From Fig.4, it can be noted that the permeability is negative over the frequency range $2.4-2.6 \mathrm{GHz}$, which confirms that the proposed unit cell is said to be a metamaterial structure.

\section{Proposed antenna design}

The antenna is printed on a FR-4 substrate with thickness of $\mathrm{h}=1$. $63 \mathrm{~mm}$, permittivity of $\varepsilon_{\mathrm{r}}=4.3$ and loss tangent of 0.0017. The evolution of tri-band monopole antenna is depicted in Fig.5. The first antenna (config. A) shows the strip line which is chosen as the monopole radiating element. The length of the strip-line was adjusted according to the general design guideline that the lowest resonance is determined when the length of the monopole $\mathrm{L}$ is approximately $\mathrm{L}=\lambda \mathrm{g} / 4$. Therefore, $\mathrm{L}_{\mathrm{a}}=8.8 \mathrm{~mm}$ to get the lowest resonance occurring at $5.8 \mathrm{GHz}$, as can be seen in Fig.7.

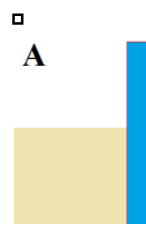

(a)

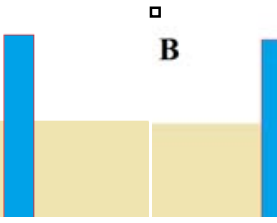

(b)

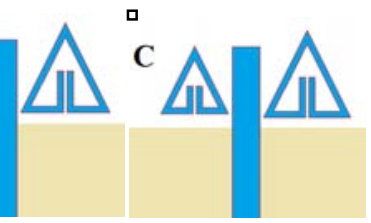

(c)
Fig.5 (a) Monopole antenna, (b) A dual-band monopole antenna with single-cell MTM loading on the right, (c) Triband monopole antenna load with two unit cells. 


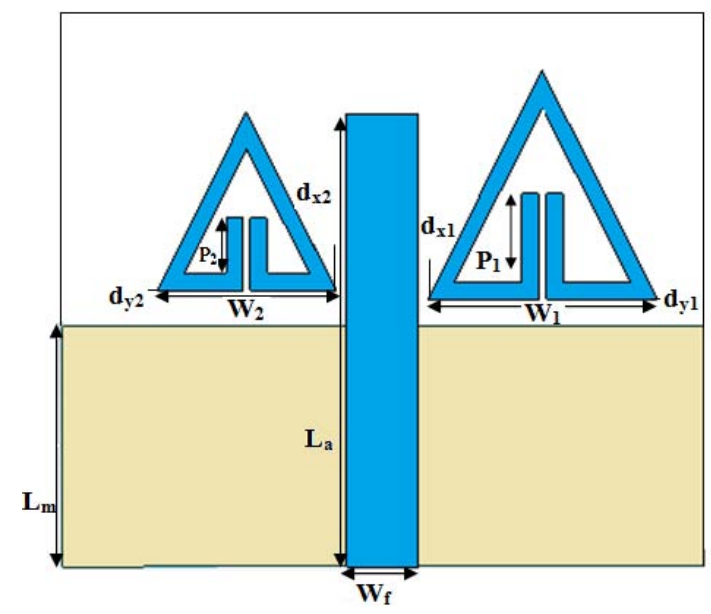

(a)

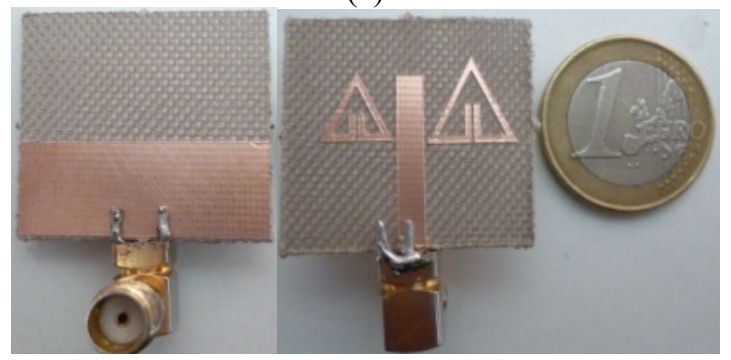

(b)

Fig.6 (a) Geometry of proposed antenna, (b) Photograph of the proposed tri-band antenna

Table 1: Dimensions of the proposed antenna

\begin{tabular}{|c|c|c|c|}
\hline Parameters & $\begin{array}{c}\text { Dimensions } \\
(\mathrm{mm})\end{array}$ & Parameters & $\begin{array}{c}\text { Dimensions } \\
(\mathrm{mm})\end{array}$ \\
\hline $\mathrm{L}_{\mathrm{m}}$ & 10 & $\mathrm{~d}_{\mathrm{x} 1}$ & 0.5 \\
\hline $\mathrm{W}_{\mathrm{f}}$ & 3 & $\mathrm{~d}_{\mathrm{x} 2}$ & 0.4 \\
\hline $\mathrm{L}_{\mathrm{a}}$ & 18.8 & $\mathrm{~d}_{\mathrm{y} 1}$ & 1.1 \\
\hline $\mathrm{W}$ & 26.6 & $\mathrm{~d}_{\mathrm{y} 2}$ & 1.5 \\
\hline $\mathrm{W}_{1}$ & 9.5 & $\mathrm{~W}_{2}$ & 7.4 \\
\hline $\mathrm{P}_{1}$ & 4.4 & $\mathrm{P}_{2}$ & 3 \\
\hline
\end{tabular}

The proposed-MTM unit cell is then placed close to the monopole antenna on a non-radiating edge on the right side and is magnetically coupled to it as illustrated in (config. B). Due to the coupling, the electric and magnetic field of the monopole interact with the proposed-MTM, then the lower frequency band isolated from the fundamental resonance is obtained.

As shown in Fig.7 a dual band is obtained to cover WiMAX /WLAN applications at $(2.5-5.82 \mathrm{GHz})$. Finally, the proposed antenna (config. C) is composed of two double proposed -MTMs with different size, which are disposed on the right and left side of the monopole antenna. By optimizing the parameters of the proposed-MTM and their positions with respect to the monopole antenna as shown in
Fig. 6 and table 1, the proposed antenna gets three distinct bands centered at about $2.5,3.62$ and $5.83 \mathrm{GHz}$ as shown in Fig.7. The resonance around 2.5 is produced by the right unit cell and the resonance at $3.62 \mathrm{GHz}$ from the left unit cell.

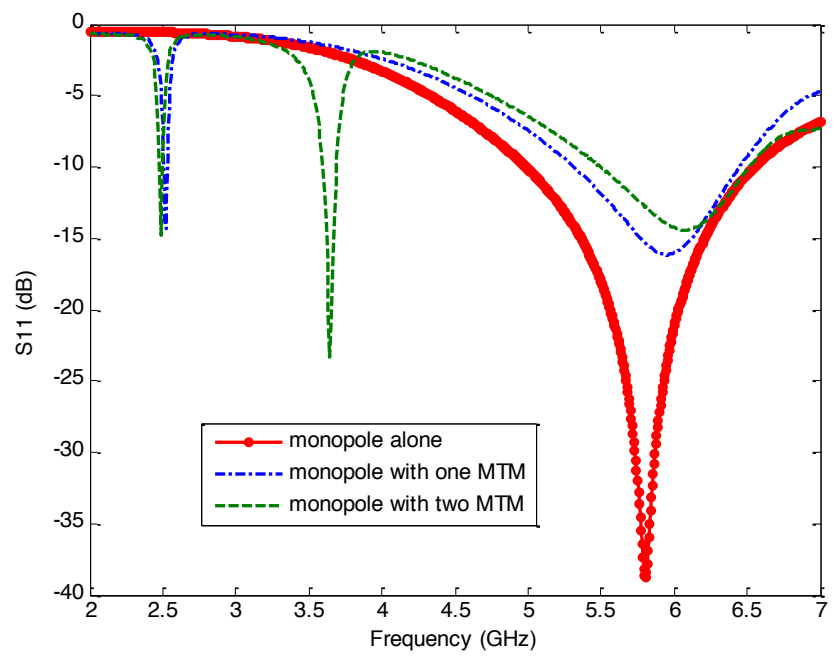

Fig.7 Simulation results of various antennas

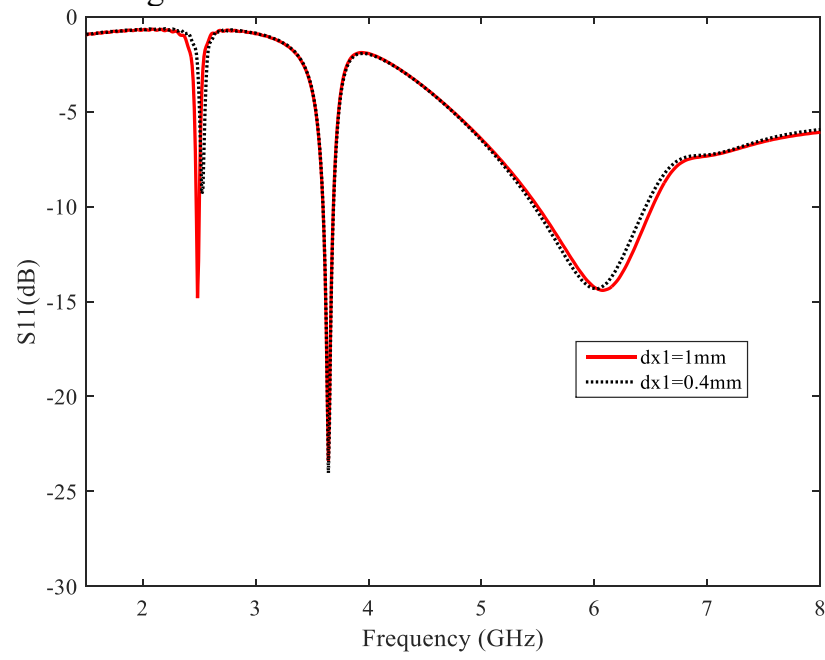

(a)

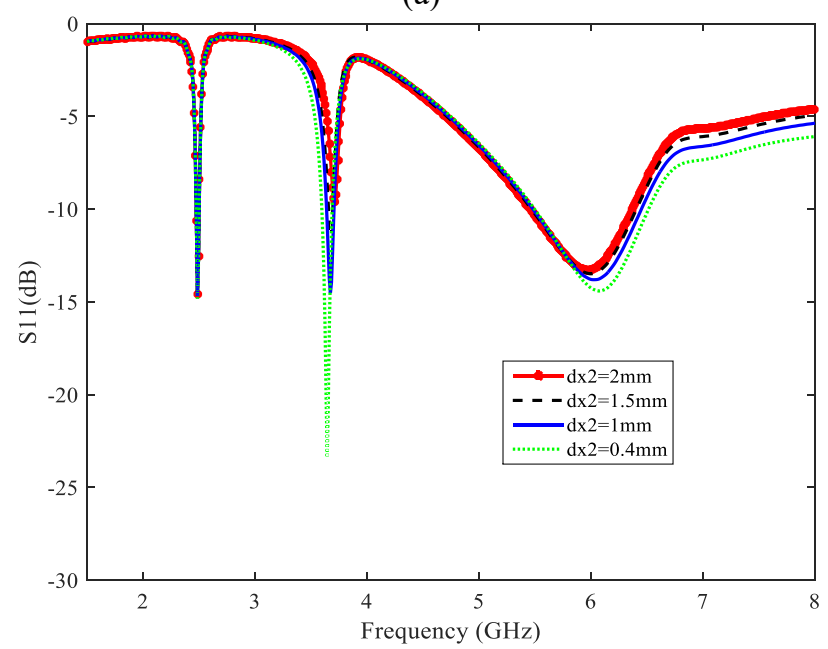

(b)

Fig. 8 Effect of the distance between cells and radiating element;(a) dx1 and (b) dx2 
Fig. 8 shows the effect of the distance between the cell and radiating element. From figure $8(a)$ as the distance $d x 1$ increases the adaptation of $\mathrm{S} 11$ decreases $(>-10 \mathrm{~dB})$ the same effect with $\mathrm{dx} 2$ as increseases the S11 deceases $(>$ 10dB).

To understand the coupling between the monopole antenna and metamaterial unit cells, the surface current distributions at three bands are analyzed as illustrated in Fig. 9. From the Fig.9 (a) and (b), it is noted that the strongest surface current distribution is mainly concentrated around the right and the left unit cell at $2.5 \mathrm{GHz}, 3.62 \mathrm{GHz}$ respectively. This means that the lower frequencies are produced by metamaterial unit cells. In the upper frequency, the current distribution is concentrated along the contour of monopole antenna and a slight of currents at the contours along the two unit cells as shown in Fig.9 (c). These explain the slight shift observed in the resonant frequency at $5.83 \mathrm{GHz}$ compared with the origin monopole antenna without two unit cells. Therefore, it indicates that the unit cell resonators make an important contribution to the surface current movement.
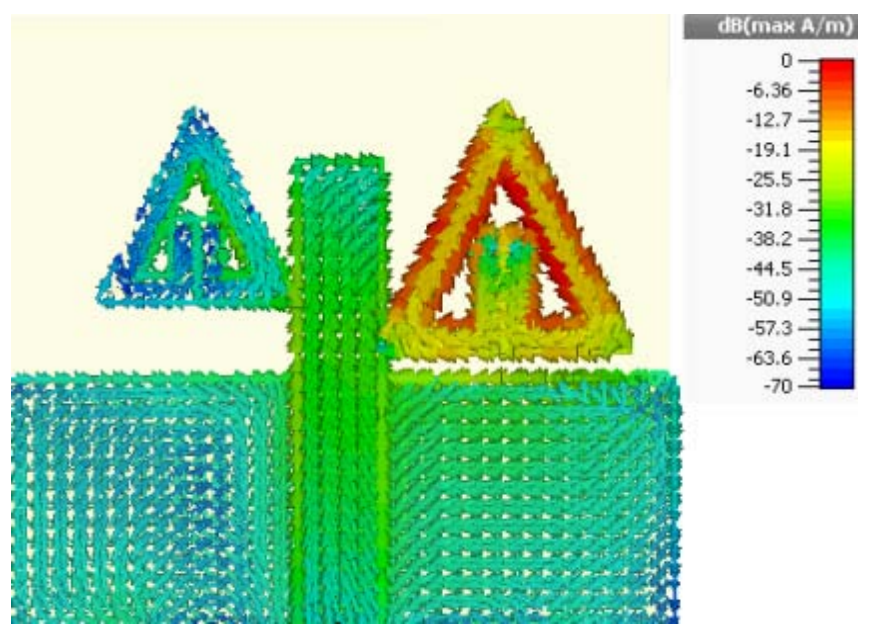

(a)
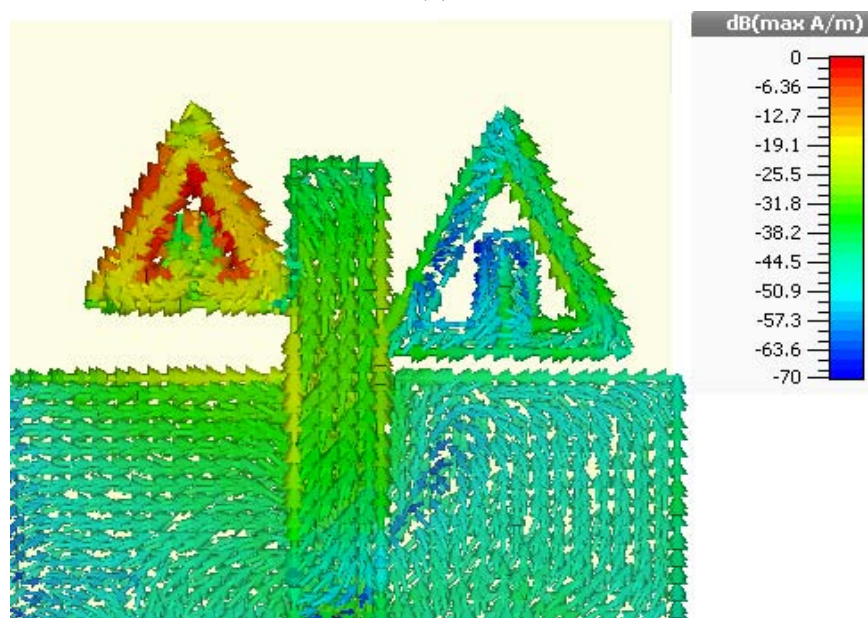

(b)

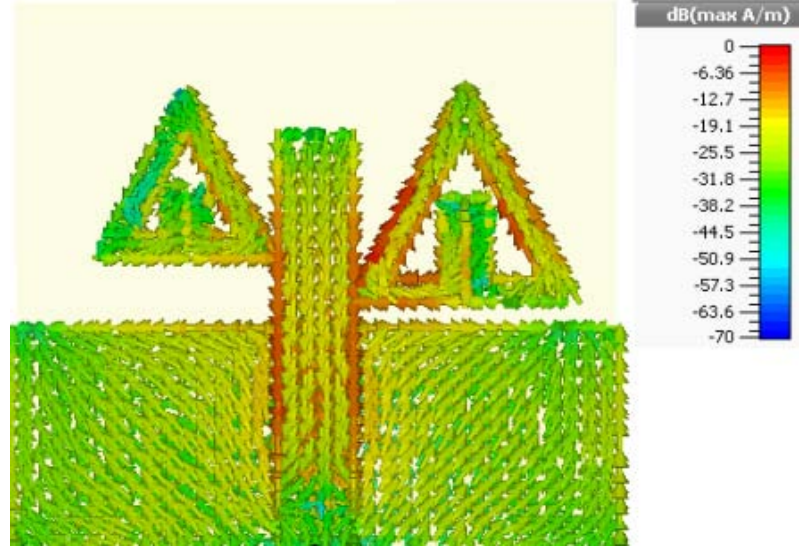

(c)

Fig.9 Simulated surface current distribution of proposed antenna at: (a) $2.5 \mathrm{GHz}$, (b) $3.62 \mathrm{GHz}$, and (c) $5.83 \mathrm{GHz}$.
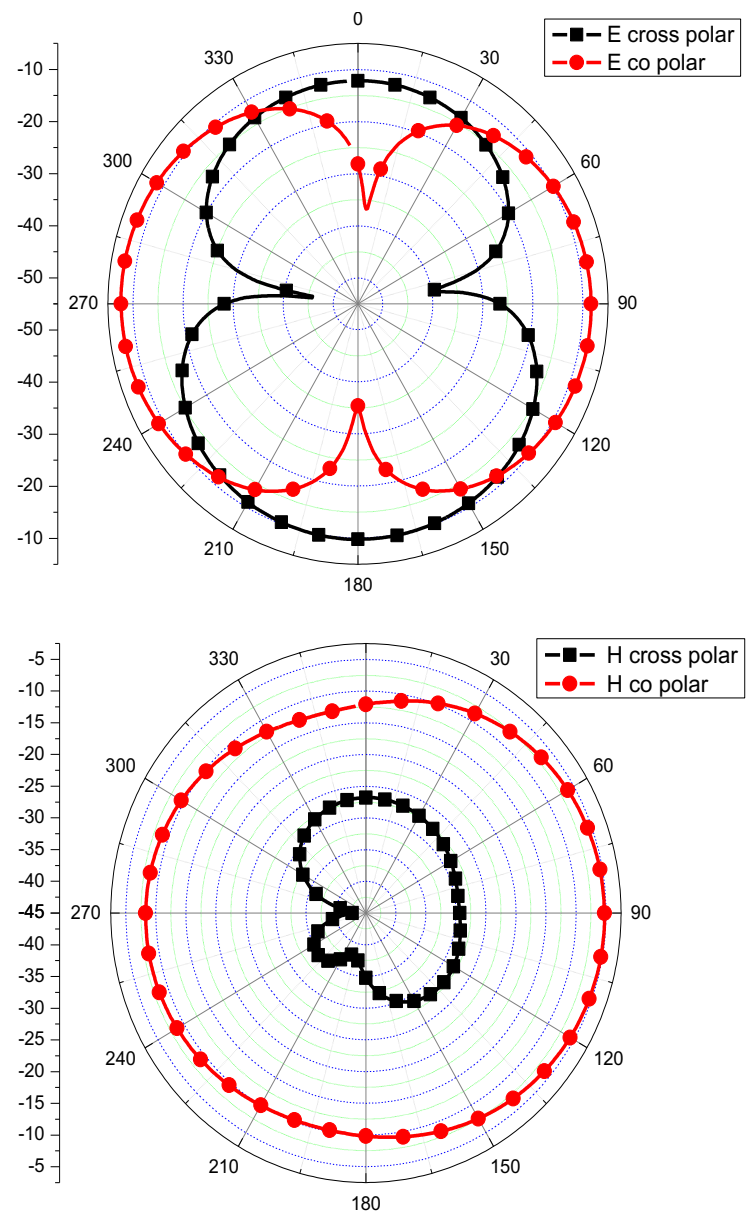

(a) 

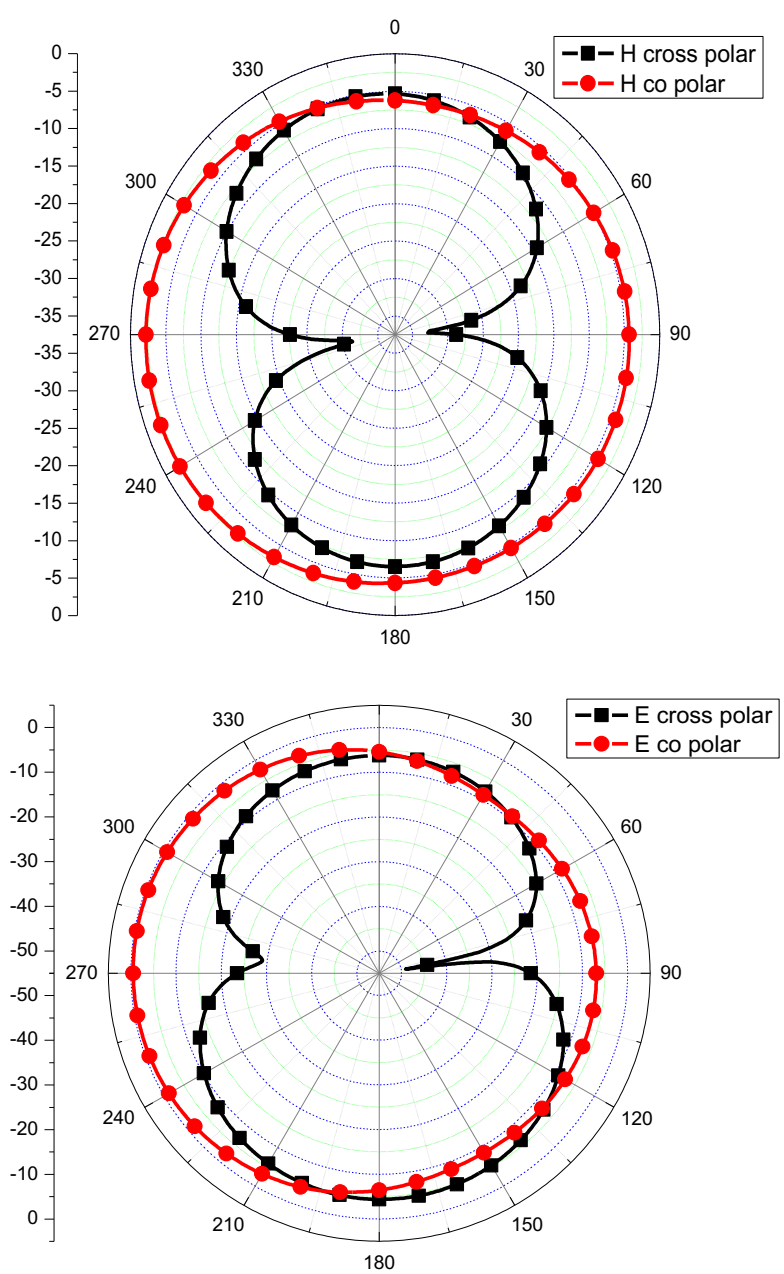

(b)

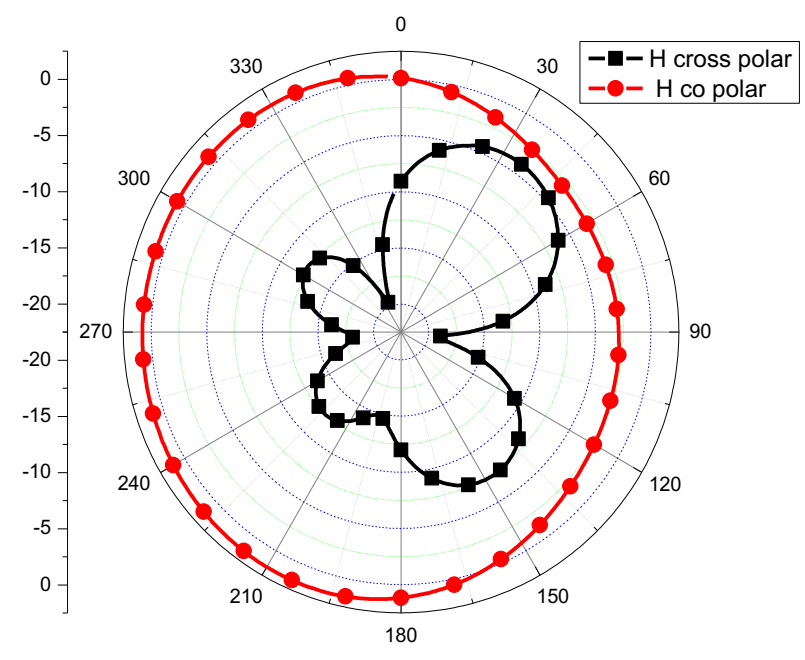

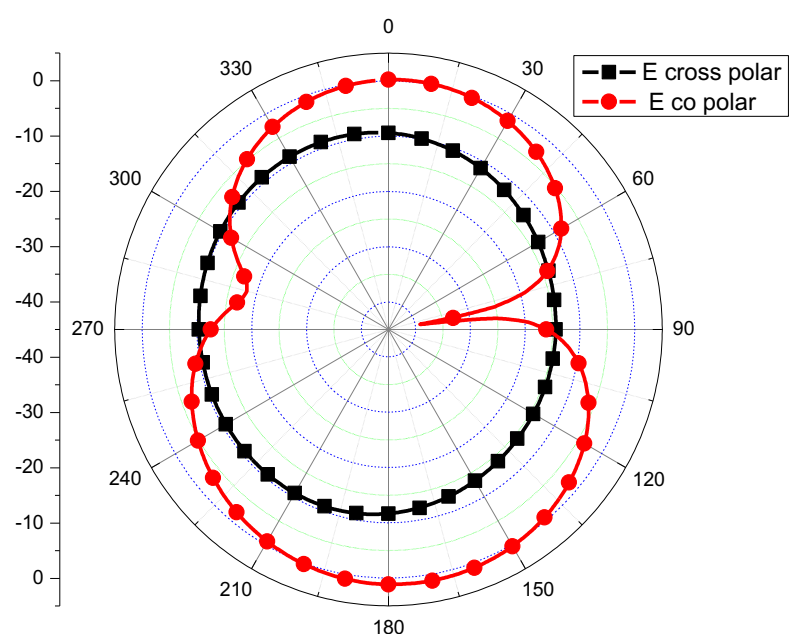

(c)

Fig.10 Radiation pattern of the proposed antenna at: (a) 2.5GHz, (b) $3.62 \mathrm{GHz}$, and (c) $5.83 \mathrm{GHz}$.

The radiation pattern of proposed antenna at $2.5 \mathrm{GHz}, 3.62$ $\mathrm{GHz}$ and $5.83 \mathrm{GHz}$ is shown in Fig.10. From the figure, it can be noted that the proposed antenna exhibits a good omnidirectional radiation in $\mathrm{H}-$ plane and bidirectional patterns in the E-plane for all the frequency bands. The gain and radiation efficiency is depicted in Fig.11,the peak gain is about $2.5 \mathrm{dBi}$.

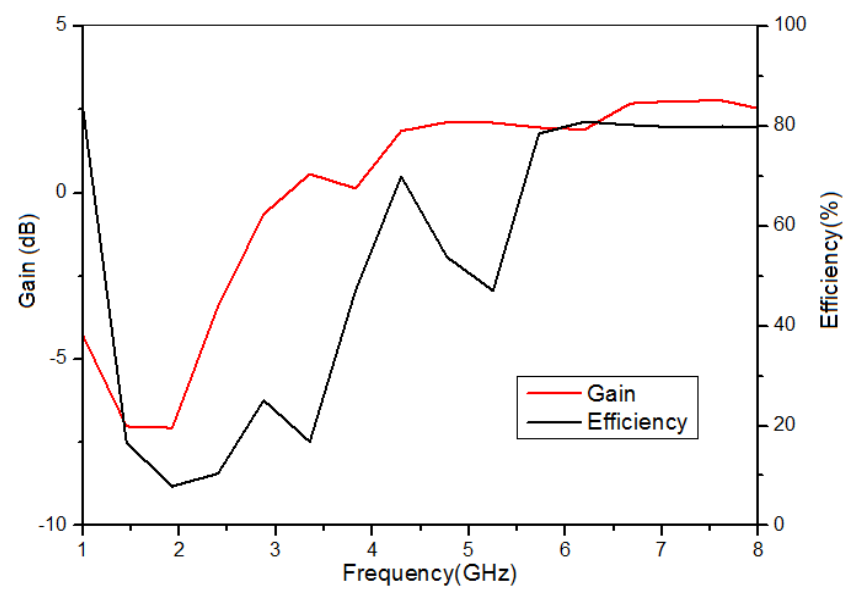

Fig.11 Gain and radiation efficiency of thr proposed structure

\section{Measurement results}

Fig.6 shows photograph of the fabricated tri-band monopole antenna. The antenna is measured by using a vector network analyzer VNA Rohde Schwarz (ZNB. 20. $100 \mathrm{KHz}-20 \mathrm{GHz}$ ). The simulated and measured $S_{11}$ versus frequency are presented in Fig.12. From the measured results, three relative impedance bandwidths with $-10 \mathrm{~dB}$ the reflection coefficient are about $10 \mathrm{MHz}(2.47-2.51 \mathrm{GHz}), 98 \mathrm{MHz}$ (3.59-3.69GHz), and $1900 \mathrm{MHz}(5.3-7.2 \mathrm{GHz})$. The measured results greatly comply with the simulated results in the $2.5 \mathrm{GHz}$ and $3.62 \mathrm{GHz}$ bands; however, a slight difference in the upper operational band is observed. This could be attributed due to the fabrication tolerance and SMA 
connector. According to the measured results, it is shown that the proposed antenna covers the WLAN/WiMAX band applications and has a compact shape compared with published antennas on Table 2 .

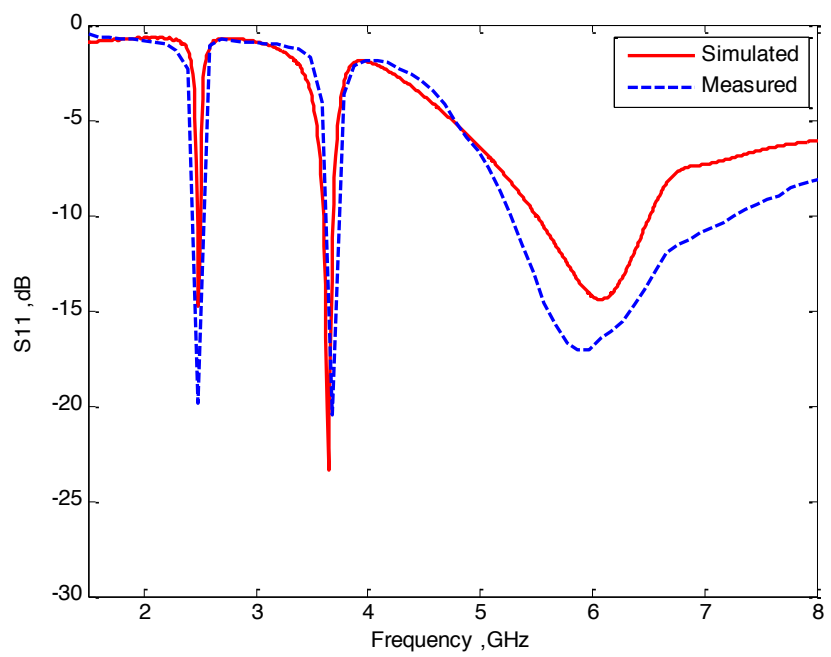

Fig.12 Simulated and measured $\mathrm{S}_{11}$ for proposed antenna.

Table 2: Comparisons between the proposed antenna and existing antennas

\begin{tabular}{|c|c|c|c|}
\hline Ref. & $\begin{array}{c}\text { Frequency range } \\
(\mathbf{G H z})\end{array}$ & $\begin{array}{c}\text { Dimensions } \\
\mathbf{L} \times \mathbf{W} \mathbf{( m m}^{\mathbf{2}} \mathbf{)}\end{array}$ & $\begin{array}{c}\text { Shape of } \\
\mathbf{M T M}\end{array}$ \\
\hline$[12]$ & $2.45,5.35,6.5$ & $28.6 \times 26.6$ & Rectangular \\
\hline$[14]$ & $1.75,3.5-4.1,4.4-5.2$ & $33 \times 30$ & $/$ \\
\hline$[15]$ & $\begin{array}{c}1.22-1.23,1.56-1.60,1.65- \\
2.88\end{array}$ & $90 \times 136$ & $/$ \\
\hline$[16]$ & $\begin{array}{c}1.48-1.87,2.39-2.71,3.02- \\
3.16\end{array}$ & $50 \times 50$ & $/$ \\
\hline$[10]$ & $2.6-4.3-5.2$ & $33.6 \times 28.2$ & $/$ \\
\hline$[17]$ & $2.45,3.5,5.5$ & $50 \times 40$ & $/$ \\
\hline$[11]$ & $1.52,1.61,2.38,3.65$ & $70 \times 40$ & $/$ \\
\hline $\begin{array}{c}\text { Proposed } \\
\text { antenna }\end{array}$ & $2.47-2.51,3.59-3.69,5.3-7.2$ & $23 \times 26.6$ & Triangular \\
\hline
\end{tabular}

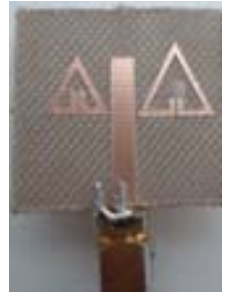

(a)

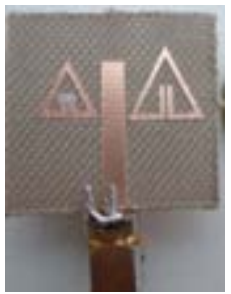

(b)

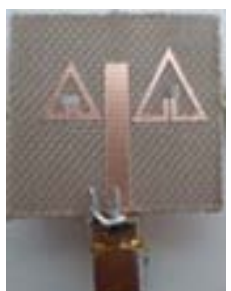

(c)
Fig.13 Geometry of antenna configuration;(a) cell-1 OFF,(b) cell-2 OFF and (c) cell-1/cell-2 OFF

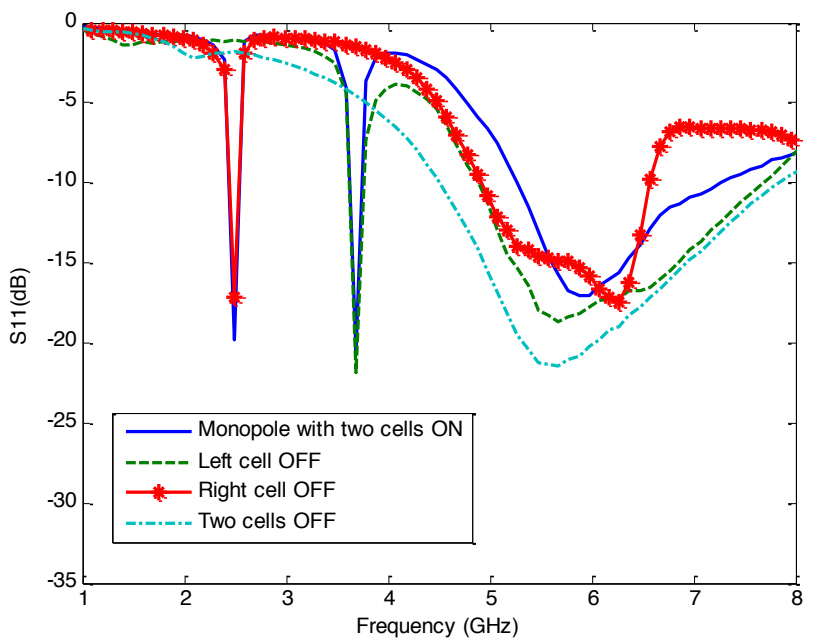

Fig.14 Measured the reflection coefficient of four cases of antenna configuration.

To study the frequency reconfiguration antenna, two switches (ON/OFF) are placed across the gaps of the two cells of proposed-MTM. By closing the switches as illustrated on Fig.13, the metamaterial characteristics of these cells are dis-appeared and their effect is deactivated. Fig.14 presents the measured results of the reflection coefficient with four different antenna configurations. As can be seen from the graph, when two switches are OFF, the antenna operates at three bands, when the right cell switch is $\mathrm{ON}$,the lower frequency at $2.5 \mathrm{GHz}$ disappears, which cancels the effect of right cell metamterial. The same thing, when the left cell switch is ON, their effect is cancelled and the frequency at $3.62 \mathrm{GHz}$ disappears this means that the switches act like notchs. Finally, when the two switches are $\mathrm{ON}$, the two lower frequencies disappear and the monopole antenna resonates at $5.82 \mathrm{GHz}$.

\section{Conclusion}

A tri-band metamaterial loaded monopole antenna for WLAN/WiMAX is presented. Then the verification of the properties or the characteristics of metamaterial on the proposed structure (triangular shaped metamaterial) was carried out. The aim was to explore the proposed structure to insert on the monopole patch antenna to get multi-band for WLAN/WiMAX applications and to reduce the size of antenna. By inserting two modified forms of triangles that act as metamaterial with different size close to the monopole antenna on the right and left side, a triple band antenna was obtained. The measured results showed good agreement in the operating bands which meet the requirements of WLAN/ WiMAX applications. In addition, the proposed antenna had an omnidirectional radiation pattern in all the operating bands. In addition, the proposed antenna had a very compact size compared with the published WiMAX/WLAN antennas. 


\section{References}

[1] Y. Xu, Y.-C. Jiao, and Y.-C. Luan, "Compact CPW-fed printed monopole antenna with tripleband characteristics for WLAN/WiMAX applications," Electronics Letters, vol. 48, pp. 1519-1520, 2012.

[2] X.Q. Zhang,Y.C. Jiao, W.H. Wang, "Compact wide tri-band slot antenna for WLAN/WiMAX applications," Electron. Lett, vol. 48, pp. 64-65, 2012.

[3] Y. F. Cao, S. W. Cheung, T. I. Yuk, "A multiband slot antenna for GPS/WiMAX/WLAN systems," IEEE Transactions on Antennas and Propagation, vol. 63, pp. 952-958, 2015.

[4] H. Chien, C. Sim and C. Lee, "Dual band meander monopole antenna for WLAN operation in laptop computer," IEEE Antennas Wireless Propag. Lett, vol. 12, pp. 694-697, 2013.

[5] R. Ghatak, RK. Mishra, DR. Poddar, " Perturbed Sier-pinski carpet antenna with CPW feed for IEEE 802.11 a/b WLAN application," IEEE Antennas Wireless Propag. Lett, vol. 7, pp. 742744, 2008.

[6] D.R. Smith, W.J. Padilla, D.C. Vier, S.C. NematNasser,S. Schultz,"Composite medium with simultaneously negative permeability and permittivity," Phys. Rev. Lett, vol. 84, pp. 41844187, 2000.

[7] B.-I. Wu, W. Wang, J. Pacheco, X. Chen, T. M. Grzegorczyk, and J. A. Kong, "A study of using metamaterials as antenna substrate to enhance gain," Progress In Electromagnetics Research, vol. 51, pp. 295-328, 2005.

[8] G. Oliveri, D. Werner, F. Bilotti, C. Craeye,"Reconfigurable electromagnetics through metamaterials," International Journal of Antennas and Propagation, vol. 2014, 2014.

[9] W. J. Krzysztofik, " Fractal Geometry in Electromagnetics Applications from Antenna to Metamaterials," Microwave Review, vol. 19, 2013.

[10] D. K. Nikos, N. K. Bourgis, T. V.Yioultsis,"Metamaterial-based electrically small multiband planar monopole antennas," IEEE Antennas And Wireless Propagation Letters, vol. 10, pp. 963 - 966, 2011.

[11] S. Dakhli, H. Rmili, J. M. Floc'h, M. Sheikh, A. Dobaie, K. Mahdjoubi, F. Choubani, R.W. Ziolkowski "Printed multiband metamaterial inspired antennas," Microwave and Optical Technology Letters, vol. 58, pp. 1281-1289, 2016.

[12] H.Cheribi, F.Ghanem,H. Kimouche, "Meta material based frequency reconfigurable antenna," Electron. Lett, vol. 49, pp. 315 - 316, 2013.

[13] D. R. Smith, S. Schultz, P. Markos, and C. M. Soukoulis, "Determination of effective permittivity and permeability of metamaterials from reflection and transmission coefficients," Phys. Rev. B, vol. 65, pp. 195104-195109, 2002.
[14] M. Barbuto, F. Bilotti, A.Toscano,"Design of a multifunctional SRR-loaded printed monopole Antenna," International Journal of $R F$ and Microwave Computer-Aided Engineering, vol. 22, pp. 552-557, 2012.

[15] J. Yeo and J. I. Lee, "Design of tri - band double dipole quasi - yagi antenna using dual co directional SRRs," Microwave and Optical Technology Letters, vol. 59, pp. 1354-1357, 2017.

[16] P. M. Paul, K. Kandasamy, and M. S. Sharawi, "A Triband Circularly Polarized Strip and SRRLoaded Slot Antenna," IEEE Transactions on Antennas and Propagation, vol. 66, pp. 5569-5573, 2018.

[17] D. Oh Kim, C. Y. Kim, D. G. Yang, and M. Sajjad Ahmad, "Multiband omnidirectional planar monopole antenna with two split ring resonator pairs," Microwave and Optical Technology Letters, vol. 59, pp. 753-758, 2017. 